\title{
Resilience amid Academic Stress: The Moderating Impact of Social Support among Social Work Students
}

\author{
Scott E. Wilks
}

\begin{abstract}
Purpose: The purpose of this study was to examine the relationship between academic stress and perceived resilience among social work students, and to identify social support as a protective factor of resilience on this relationship. A conceptual model of moderation was used to test the role of social support as protective. Methods: The sample consisted of 314 social work students (BSW=144; MSW=170) from three accredited schools/programs in the southern United States. Voluntary survey data were collected on demographics and constructs of academic stress, family support, friend support, and resilience. Hierarchical regression analysis was conducted to show the composite impact of demographic and model factors on the resilience outcome. Moderation was tested using a traditional regression series as guidelines of moderation with continuous variables. Path analyses illustrated main effects and moderation in the study's conceptual model. Results: The sample reported moderate levels of academic stress and social support, and a fairly high level of resilience. Academic stress negatively related to social support and resilience. Social support positively influenced resilience. Academic stress accounted for the most variation in resilience scores. Friend support significantly moderated the negative relationship between academic stress and resilience. Conclusion: The current study demonstrated the likelihood that friend support plays a protective role with resilience amid an environment of academic stress. Implications for social work faculty and internship agency practitioners are discussed.
\end{abstract}

Keywords: Academic stress; resilience; social support; social work students

A number of demands reportedly comprise academic stress: course requirements; time management issues; financial burdens; interactions with faculty; personal goals; social activities; adjustment to the campus environment; and lack of support networks (Kariv \& Heiman, 2005; Misra, 2000; Von Ah, Ebert, Ngamvitroj, Park, \& Hang, 2004). Specific to this latter demand is an implicit assumption that existence or upsurge of social support may moderate, to some degree, academic stress. Social support is often deemed a buffer against the negative effects of stress, including stress in an academic context (Steinhardt \& Dolbier, 2008).

Several studies have revealed the impactful relationship between social support and academic stress among a variety of academic disciplines and college student populations. Heiman (2006) noted that academic perceptions are significantly attributable to external factors, including social networks, among university students with learning disabilities. Negga, Applewhite, and Livingston (2007) showed that greater levels of social support were significantly related to lower levels of stress among African American students at historically Black colleges and universities. MacGeorge, Samter, and Gillihan (2005) observed a moderating effect of informational, supportive communicative behaviors from

Scott E. Wilks, Ph.D., is an assistant professor at the School of Social Work, Louisiana State University, as well as a John A. Hartford Foundation Faculty Scholar in Geriatric Social Work.

Copyright (C) 2008 Advances in Social Work Vol. 9 No. 2 (Fall 2008), 106-125 
family and friends on the relationship between academic stress and psychological health students in communication classes. MacGeorge et al. explained that "the association between academic stress and depression decreased as informational support increased" (p. 369). Cahir and Morris (1991) stated that a principal component of stress among graduate psychology students is limited by emotional support from friends.

A recent study by Steinhardt and Dolbier (2008) emphasized the interactional relationship between academic stress and social support among students with various majors at undergraduate, graduate, and doctoral levels. They noted that the stressful academic environment of the college student warrants research with outcomes that reflect the student's ability to adapt to and/or overcome adversity. Such is the case with the current study of social work students. The purpose of this study is to examine the potential, moderating role of social support in the relationship between academic stress and successful adaptation to stress, i.e., resilience. Conceptually specific to this study, a moderator is a phenomenon that interacts with academic stress and ameliorates the relationship between stress and resilience (see Baron \& Kenny, 1986). The literature review explicates the three primary constructs for this study, beginning with academic stress.

\section{LITERATURE REVIEW}

\section{Academic Stress}

For many students, the pursuit of higher education is a time of transition marked by a set of demands germane to the setting. Academic stress is the product of a combination of academic related demands that exceed the adaptive resources available to an individual. If a student is unable to cope effectively with academic stress, then serious psycho-socialemotional health consequences may result (Arthur, 1998; MacGeorge, Samter, \& Gillikan, 2005; Tennant, 2002). Zaleski and colleagues (1998) found that as the number of stressful life events increased for college students, physical symptoms also increased. Students who experience mental and physical health problems are then at greater risk for poor academic performance, thus increasing academic stress and perpetuating a cycle of stress, maladaptive coping, and compromised health (Haines, Norris, \& Kashy, 1996; Ward Struthers, Perry, \& Menec, 2000). Interrelational factors often coincide with academic stress. Many of these are related to juggling multiple roles, including interpersonal relationships in the home and at work. These factors may dictate time management skills (Misra, McKean, West, \& Russo, 2000) and consequently the decision of traditional, full time enrollment versus part time enrollment, also suggested as a source of stress among the general college student population (Ting, Morris, McFeaters, \& Eustice, 2006).

As Ting et al. (2006) asserted, the strain of multiple roles is evident among social work students. Like other care or helping professions, they must adapt not only to their role as students, but also to the obligations inherent to their chosen profession (Dziegielewski, Roest-Martl, \& Turnage, 2004; Kamya, 2000). Social work students are vulnerable to high levels of psychological distress, and the education period may be more stressful than the actual social work career (Pottage \& Huxley, 1996; Tobin \& Carson, 
1994). In addition to the more common stressors faced by college students, social work students have the added burden of coping with the role expectations of professional placement experiences. Sun (1999) found that students entering their first practicum placement had an array of concerns: role(s) in the placement agency; skill level in working with clients; personal responses to clients (e.g., stereotyping); and quality of supervision they receive.

Contextually related to resilience research, academic stress can be viewed as risk. Risk implies an individual or environmental hazard that increases susceptibility of a negative outcome (Masten, 2001). Academic stress is a risk factor that may lead social work students to negative health outcomes, particularly psychological distress (Steinhardt $\&$ Dolbier, 2008). Yet, few studies have examined the resources available to social work students as they attempt to temper this risk (Rompf, Royse, \& Dhooper, 1993; Gelman, 2004). Consequential to a recent review of scholarly literature, there appears a deficit of social work research that examines aforementioned resources with an explicit, resultant outcome of adaptational success. Thus, a brief review of a construct of adaptational success, along with the functions of resources that temper risk and consequentially enhance such success, ensues.

\section{Resilience, Risk and Protective Factors}

Resilience is a successful outcome of healthy adaptations during stressful life events (Rutter, 1990). Resilience is often viewed in the psychological context insomuch as it refers to cognitive capacity to avoid psychopathology despite difficulties (Tugade, Fredrickson, \& Barrett, 2004). It is a psychological phenomenon as it is a perception of inner strength that allows for the physical manifestation of that strength, i.e., the quick recovery from disruptions in functioning and return to previous level of functioning (Carver, 1998; Steinhardt \& Dolbier, 2008). Individuals who are highly resilient exhibit adaptive coping skills and often convert stressors into opportunities for learning and development. In a sample of college students, Campbell-Sills and colleagues (2006) found that resilience was positively related to task-oriented coping, or employing active, problem-focused to address stressors (Kariv \& Heiman, 2005). Similarly, Clifton and colleagues (2004) found that, of several demographic and environmental variables, problem-focused coping strategies as well as perceived control had the largest effects on academic achievement. Ward Struthers and colleagues (2000) also found that students who used problem-focused coping strategies performed better academically compared to students who used emotion-focused coping strategies. Therefore, a student's level of resilience and the manifestations of that resilience are related to effective adaptive resources to academic stress.

These adaptive resources can be viewed as protective in the resilience research context. The protective factor is often viewed as the opposite pole of the risk factor (Ortega, Beauchemin, \& Kaniskan, 2008). Rutter (1990) defined a resource, internal and external, as protective if it moderates risk, tempering the negative impact of risk on resilience. Internal resources related to stress and coping include hardiness, self-esteem, and self-efficacy (Kamya, 2000; Kobasa, 1979; Zaleski, Levey-Thors, \& Schiaffino, 1998). These concepts do not exist in a vacuum, and associations between protective 
factors are common. For example, Kamya's study found that greater levels of hardiness were associated with greater self-esteem among social work students. In turn, individuals with greater self-esteem are better able to cope with stress and achieve higher GPAs (Clifton, Perry, Stubbs, \& Roberts, 2004). The interrelatedness of these concepts further suggests the existence of an overarching internal strength such as resilience.

In addition to internal protective resources, external or environmental factors may interact with academic stress as protective resources. Research (e.g., Werner \& Smith, 1992) has shown that social support can be a robust protective factor when individuals experience various forms of stress. The question relevant to the current study is whether social support functions as a protective factor within the process of the social work student's academic stress-resilience relationship. Discussed next are examples of the utilization of this external protective factor in the educational context relevant to the current study.

\section{Social Support}

The beneficial impact of social support has been associated with both physical and mental health outcomes. Greater levels of social support are associated with lower levels of depression, fewer episodes of negative life events, more positive mood, and greater life satisfaction (Aldwin, 1994; Balk, 1995; Demakis \& McAdams, 1994; Ford \& Procidano, 1990; Losel \& Bliesener, 1990; Sarason, Shearin, Pierce, \& Sarason, 1987). Within higher education settings, a palpable social support for students is faculty. Support from professors and student friends have been positively associated with self-esteem (Clifton, et al., 2004). Also, the lack of social support from professors had a negative effect on the academic performance of students (Clifton, 1997). Student perceptions of social support have also been positively associated with health-promoting behaviors such as exercise, good nutrition, and avoidance of substance abuse (Hubbard, Muhlenkamp, \& Brown, 1984; Martinelli, 1999). Conversely, research among college students suggests that withdrawing from social support relates to negative life satisfaction (Mori, 2000). Social support examined in this research is the perceived availability of resources provided by family and friends that assist the person in everyday activities (Rayle, 2006). Analogous to previous research with measures of social support (e.g., Dolbier \& Steinhardt, 2000; Procidano \& Heller, 1983), the current study does not limit the defined parameters of family member and friend; rather, it defers the concepts of a family member and friend to those strictly defined by the research participant.

Most, but not all, studies propose that social support is inevitably perceived as supportive. MacGeorge et al. (2005) highlighted the beneficial impact of supportive behaviors from family and friends on the student's psychological health. Similarly, Zaleski et al. (1998) noted that social support provided by friends was positively associated with adjustment to college life. Yet, Zaleski et al. noted that support from family appeared to worsen problems experienced by students.

Research in this area among social work students, albeit sparse, suggests the beneficial nature of social support in stress-related contexts. Forte (1995) emphasized support of social work student classmates as positive on course anxiety. Rosenblatt and 
Mayer (1975) underscored the guidance of fellow students as important to the success of coping with field supervisory conflicts. The purpose of the present study was to obtain a better understanding of the protective role of social support amid the relationship of academic stress and resilience among social work students. To serve this purpose, a moderation model was adapted for the current study using the three integral elements of resilience research (Masten, 2001; Rutter, 1990): risk, resilience, and the protective factor.

\section{CONCEPTUAL MODEL}

The model for the present study (Figure 1) fused Glass and Singer's (1972) traditional understanding of moderation with Wang, Badley, and Gignac's (2006) illustrative models. Glass and Singer (1972) noted that the effect of a particular factor on an outcome can be based on the presence or level of a third variable, i.e., a moderator. Wang et al.'s (2006) illustrated three similar moderator models using the primary factor, outcome, and potential moderator. These models are distinguished by whether significant relationships exist between the moderator and the other model variables.

The model in the current study (Figure 1) theorizes that the effect of risk on the resilience outcome depends on the presence or level of the moderator. The risk in the current study is academic stress (AS). The moderators tested separately are two forms of social support: family support $(\mathrm{FaS})$ and friend support (FrS). The outcome in the model is resilience.

\section{FIGURE 1: Input Model: Moderating Function of Social Support on the Relationship of Academic Stress and Resilience of Social Work Students}

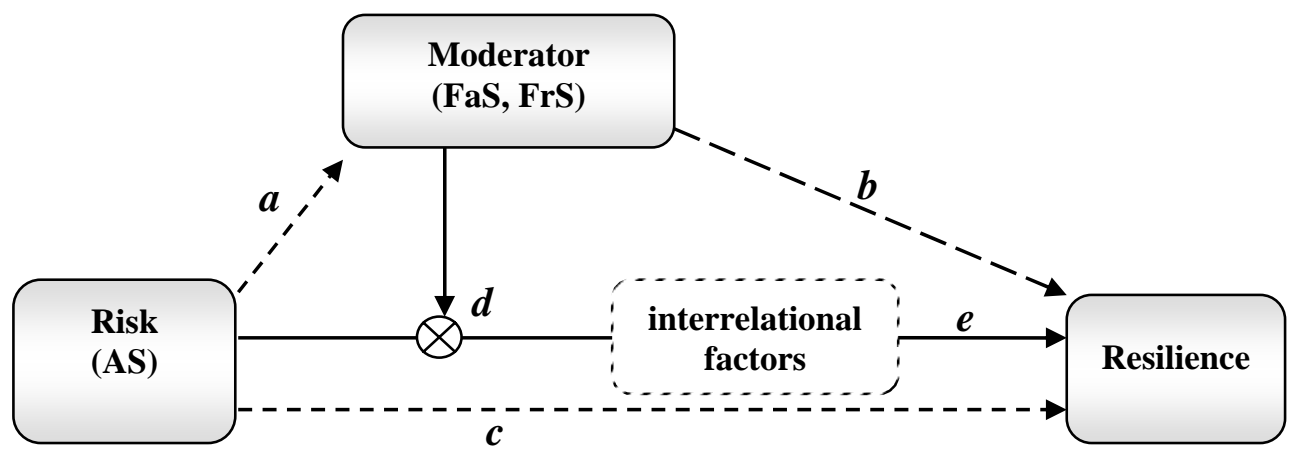

Abbreviations: AS - academic stress; FaS - family support; FrS - friend support

The dashed connectors represent three direct paths that are not statistically critical to observing moderation (Wang et al., 2006); nonetheless, these paths are worth noting for descriptive purposes: academic stress $\rightarrow$ social support (path $a$ ), social support $\rightarrow$ resilience (path $b$ ), and academic stress $\rightarrow$ resilience (path $c$ ). The solid connector represents the 
critical path in moderation analysis; the circled $X$ represents the interaction of AS and the moderator on the resilience outcome (path $d$ ). Previously mentioned, interrelational factors have been exposed as potentially influential with AS. Accordingly, the inclusion of demographic factors relating to home, occupational, and educational interpersonal relationships - marital status, number of children, employment status, and academic status - was deemed relevant as controls in the interaction path (path $e$ ). Two separate models were used to distinguish social support by its two factions, familial and friend support. Moderation exhibited by family or friend support would offer preliminary evidence of social support as a protective factor of resilience among this student population.

\section{METHOD}

\section{Research Questions and Design}

The following research questions guided this inquiry:

- To what extent do social work students perceive academic stress?

- What is their level of overall social support?

- What is their level of support among family members?

- What is their level of support among friends?

- What is their perceived level of resilience?

- Do family support and friend support moderate the relationship between academic stress and perceived resilience?

The study used a correlational analysis via self-report questionnaires distributed to BSW and MSW students. Operationally, within a correlational analysis framework, a moderator is a third variable that affects the zero-order (bivariate) correlation between two other variables. Such moderation is observed via a significant interaction effect between a primary independent variable and the proposed moderating variable on a particular outcome (Baron \& Kenny, 1986; Wang et al., 2006).

\section{Sampling}

The sampling frame consisted of social work students from three schools/programs of social work: one with an accredited BSW program, one with an accredited MSW program, and one with both accredited programs (Council on Social Work Education, 2006). All are academic units within public universities located in the southern United States. Surveys were distributed by participating instructors to students in BSW and MSW classes at all levels within the programs. Cover letters attached to each survey provided information necessary for informed consent, including the voluntary nature participation and no influence of grade based on participation. Surveys completed by students with non-social work majors were collected but not analyzed, as they were few 
and represented data outside the study's purview. Three hundred fourteen students (BSW, $\mathrm{n}=144$; MSW, $\mathrm{n}=170$ ) participated in the study.

\section{Measures}

The survey instrument solicited demographic data on gender, ethnicity, age, and interrelational demographics - marital status, number of children, employment status (full time, part time, unemployed), enrollment status (full time, part time), and academic level (BSW, MSW). The remaining empirical measures on the survey are discussed below.

Academic stress. The risk in the current study, academic stress, was measured aptly using Kohn and Frazer's (1986) Academic Stress Scale (ASS). The 35-item ASS measures the extent of academic worry across three subscales: physical, psychological, and psychosocial (Ginsberg \& Gapen, 2008). Examples of physical stressors include temperature, lighting, and noise in the classroom. Psychological stressors are emotional consequence that results from events such as excessive homework, forgotten assignments, and studying for exams. Psychosocial stressors are similar to psychological stressors with the inclusion of interpersonal interactions; psychosocial events include evaluating classmates' work and preparedness to respond in class. Item responses range on a 10-point Likert format from 0-not stressful to 9-extremely stressful. Item responses are summed then averaged. A higher mean indicates greater academic stress. Prior research (Burnett \& Fanshawe, 1996; Kohn \& Frazer, 1986) found good-to-excellent internal reliability for the entire measure $(\alpha=0.92)$ and on each subscale and factor $(\alpha=$ $0.73-0.84)$, suggested predictive validity.

Social Support. Two forms of social support serve as protective, moderating factors tested in the current study. Family support and friend support were measured via Maton et al.'s (1996) shortened, 20-item version of the Perceived Social Support Scale (PSSS20; Procidano \& Heller, 1983). The PSSS20 measures perceived quantity and quality of social support with two, 10-item subscales for familial and friend support. Responses range on a 5-point Likert format from strongly agree to strongly disagree. Total scores range 0 to 40 on each subscale; a higher score indicates greater perceived family or friend support. Shute and Spitzberg (2003) cited previously tested properties of the PSSS20, including a solid range of internal consistency coefficients $(\alpha=0.79-0.94)$. Wording on each subscale is similar except for the family and friends distinction. Item examples include the following: "My family/friends give me the moral support I need"; "I rely on my family/friends for emotional support"; and "My family/friends are good at helping me solve problems."

Resilience. The outcome of resilience in the current study requires an explicit measure of such. Neill and Dias (2001) revealed a 15-item Resilience Scale (RS15) that solicits data on positively stated self-descriptions relating to the psychological characteristic of resilience, i.e., the capacity for successful adaptation following exposure to stressful life events (Werner, 1989, as cited in Neill \& Dias, 2001). Responses range on a 7-point Likert format from strongly disagree to strongly agree. Summed item responses are averaged. Mean scores range from 1 to 7; a higher mean indicates greater overall perceived resilience. Past research (Neill \& Dias, 2001; Skehill, 2001) reported a 
good-to-excellent range of internal reliability coefficients on the S-RS $(\alpha=0.85-0.91)$. Examples of item content relate to self-discipline, determination, and finding meaning in life.

\section{Data Analyses}

Descriptive statistics and correlations were calculated for demographics and conceptual model variables: academic stress, family support, friend support, and resilience. Hierarchical regression analysis was conducted to show the composite impact of the combined demographic factors, academic stress, and both forms of social support on the resilience outcome. Using Baron and Kenny's (1986) guidelines of moderation with continuous variables, resilience was regressed on academic stress, on social support, and on the interaction of academic stress and social support. After calculating an aforementioned interaction term, moderation was tested by observing any significant interaction effect on resilience while controlling for theoretically confounding, demographic factors relating to interrelational issues. Path analyses illustrated main effects and moderation in the study's conceptual model.

\section{RESULTS}

\section{Sample Characteristics}

Three hundred fourteen students constituted the sample size. Females comprised the vast majority of the sample $(89 \%, \mathrm{n}=278)$. The average age was approximately 26 years, ranging from ages 19 to 53 . The highest reported ethnicity was White $(79 \%, n=239)$ followed by African American $(16 \%, n=48)$. In terms of number of children, almost eight out of ten $(\mathrm{n}=242)$ reported having none. The plurality of the student sample reported an employment status of part time $(44 \%, n=133)$, while only $19 \%(n=155)$ work full time. A great majority in the sample reported full time enrollment in their social work program $(91 \%, n=280)$. The distribution between undergraduate and graduate students was fairly balanced, as MSW students represented a slight majority $(54 \%, n=169)$. Table 1 reveals complete demographic statistics from the social work student sample.

\section{Descriptives, Correlations}

Looking at the primary variables, the sample of social work students reported moderate levels of academic stress (AS), family support (FaS), and friend support (FrS); and a moderately high degree of resilience (RS). Correlational analysis confirmed significant bivariate relationships among all of the primary variables except between AS and FrS. Table 2 presents correlations and descriptives among the primary variables.

Hierarchical regression analysis explained variation in resilience scores based on the composite impact of all factors, including demographics. Upon initial inclusion of demographics, the ordering of primary factors was based on magnitude of main effect on the outcome. To avoid redundancy, overall social support was examined by its subcategories. Table 3 presents results from the hierarchical regression analysis. 
TABLE 1: Sample Demographic Characteristics $(N=314)$

\begin{tabular}{|c|c|c|c|}
\hline Characteristics & n (valid \%) & $M(S D)$ & Median \\
\hline \multicolumn{4}{|l|}{ Gender } \\
\hline Female & $278(89 \%)$ & & \\
\hline Male & $36(11 \%)$ & & \\
\hline \multicolumn{4}{|l|}{ Ethnicity } \\
\hline African American & $48(16 \%)$ & & \\
\hline Asian & $9(3 \%)$ & & \\
\hline Caucasian & $239(79 \%)$ & & \\
\hline Other & $7(2 \%)$ & & \\
\hline \multicolumn{4}{|l|}{ Marital Status } \\
\hline Single & $208(67.8 \%)$ & & \\
\hline Married & $66(21.6 \%)$ & & \\
\hline Divorced & $21(6.7 \%)$ & & \\
\hline Cohabitating & $12(3.8 \%)$ & & \\
\hline \multicolumn{4}{|l|}{ Number of children } \\
\hline 0 & $242(79 \%)$ & & \\
\hline 1 & $34(11 \%)$ & & \\
\hline 2 & $20(6.5 \%)$ & & \\
\hline $3+$ & $11(3.5 \%)$ & & \\
\hline \multicolumn{4}{|l|}{ Employment status } \\
\hline Full time & $55(19 \%)$ & & \\
\hline Part time & $133(44 \%)$ & & \\
\hline Unemployed & $111(37 \%)$ & & \\
\hline \multicolumn{4}{|l|}{ Enrollment status } \\
\hline Full time student & $280(91 \%)$ & & \\
\hline Part time student & $28(9 \%)$ & & \\
\hline \multicolumn{4}{|l|}{ Academic level } \\
\hline BSW & $143(46 \%)$ & & \\
\hline MSW & $169(54 \%)$ & & \\
\hline Age & & $25.2(6.43)$ & 23.0 \\
\hline
\end{tabular}


TABLE 2. Correlations and Descriptive Statistics among the Primary Conceptual Variables $(\mathrm{N}=314)$

\begin{tabular}{|c|c|c|c|c|c|c|}
\hline Variable & 1 & 2 & 3 & 4 & $M$ & $S D$ \\
\hline 1. $\mathrm{AS}$ & --- & & & & 4.7 & 1.38 \\
\hline 2. FaS & $-0.21^{+}$ & --- & & & 30.8 & 8.07 \\
\hline 3. $\mathrm{FrS}$ & -0.12 & $0.34^{+}$ & --- & & 31.4 & 5.63 \\
\hline 4. $\mathrm{RS}$ & $-0.38^{+}$ & $0.30^{+}$ & $0.29^{+}$ & --- & 5.8 & 1.01 \\
\hline
\end{tabular}

TABLE 3. Results from Hierarchical Regression Analysis Predicting Resilience Scores

\begin{tabular}{|c|c|c|c|c|}
\hline & & $\Delta R^{2}$ & $F$ & $\beta$ \\
\hline \multicolumn{5}{|l|}{ Step 1} \\
\hline & Demographics (non-interrelational) & & & \\
\hline & Gender & & & .076 \\
\hline & Ethnicity & & & .023 \\
\hline & Age & & & .168 \\
\hline & $R^{2}$ & .013 & & .101 \\
\hline \multicolumn{5}{|l|}{ Step 2} \\
\hline & Demographics (interrelational) & & & \\
\hline & Marital status & & & .129 \\
\hline & No. of children & & & -.096 \\
\hline & Employment status & & & .040 \\
\hline & Enrollment status & & & .101 \\
\hline & Academic level & & & .018 \\
\hline & $R^{2}$ & .040 & .99 & \\
\hline \multicolumn{5}{|l|}{ Step 3} \\
\hline & AS & .142 & $4.62^{+}$ & \\
\hline \multicolumn{5}{|l|}{ Step 4} \\
\hline \multirow{2}{*}{\multicolumn{5}{|c|}{$5.68^{+}$}} \\
\hline & FrS & .032 & $6.10^{+}$ & \\
\hline$R^{2}$ total & & .266 & & \\
\hline
\end{tabular}

${ }^{+} p \leq .01$; Abbreviations: $\mathrm{AS}$ - academic stress; $\mathrm{FaS}$ - family support; $\mathrm{FrS}$ - friend support 
Following Baron and Kenny's (1986) moderation suggestions, a three-equation series regressed RS on: (a) the IV of interest, AS; (b) the tested moderator; and (c) their interaction. Table 4 shows results of this series, conducted twice to test separate moderators: family support (series 1) and friend support (series 2).

\section{TABLE 4. Results from Baron \& Kenny's Regression Series for Moderation}

\begin{tabular}{lll}
\hline \multirow{2}{*}{ Regression Equation } & Series 1: & Series 2: \\
& FaS as Moderator & FrS as Moderator \\
\hline \multirow{2}{*}{ a) RS regressed on AS } & $R^{2}=0.15, F=35.30^{+}$, & $R^{2}=0.15, F=35.30^{+}$, \\
& $\beta=-0.382$ & $\beta=-0.382$ \\
& $R^{2}=0.09, F=19.89^{+}$, & $R^{2}=0.09, F=19.15^{+}$, \\
b) RS regressed on moderator & $\beta=0.296$ & $\beta=0.291$ \\
& & $R^{2}=0.03, F=4.71^{*}$, \\
c) RS regressed on interaction & $R^{2}=0.01, F=1.23$, & $\beta=-0.149$ \\
(moderation path) & $\beta=-0.077$ & \\
\hline
\end{tabular}

${ }^{*} p<.05,{ }^{+} p<.01$

Abbreviations: AS - academic stress; $\mathrm{FaS}$ - family support; $\mathrm{FrS}$ - friend support; RS - resilience

Figures 2 and 3 show similar path models of moderation with distinct moderators: family support (Fig. 2), and friend support (Fig. 3). The direct path of AS on the resilience outcome in both models was negative and moderately strong $(-.382, p<.01$, $\left.r^{2}=.15\right)$.

\section{FIGURE 2. Output: Family Support Moderation Model}

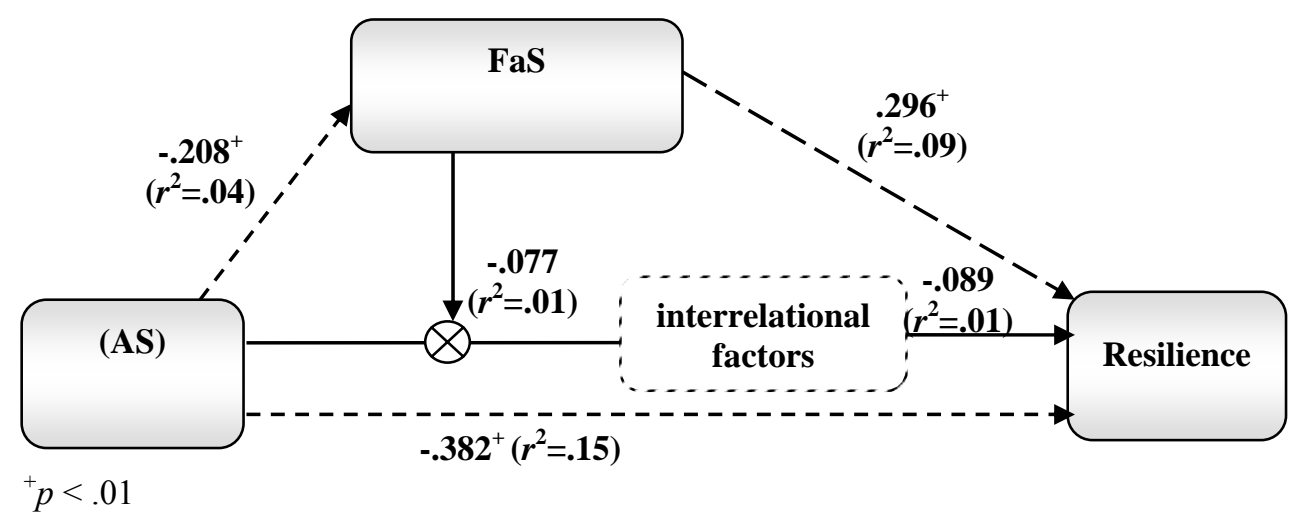

Abbreviations: AS - academic stress; FaS - family support; FrS - friend support

Figure 2 illustrates the path coefficients in the family support moderation model. The moderation effect (interaction) of AS $x \mathrm{FaS}$ on the outcome was non-significant initially 
$\left(-.077, p=.268, r^{2}=.01\right)$. Upon controlling for interrelational factors, the moderation effect remained non-significant and its inverse effect to resilience slightly increased (-.089, $p=.214, r^{2}=.01$ ).

\section{FIGURE 3. Output: Friend Support Moderation Model}

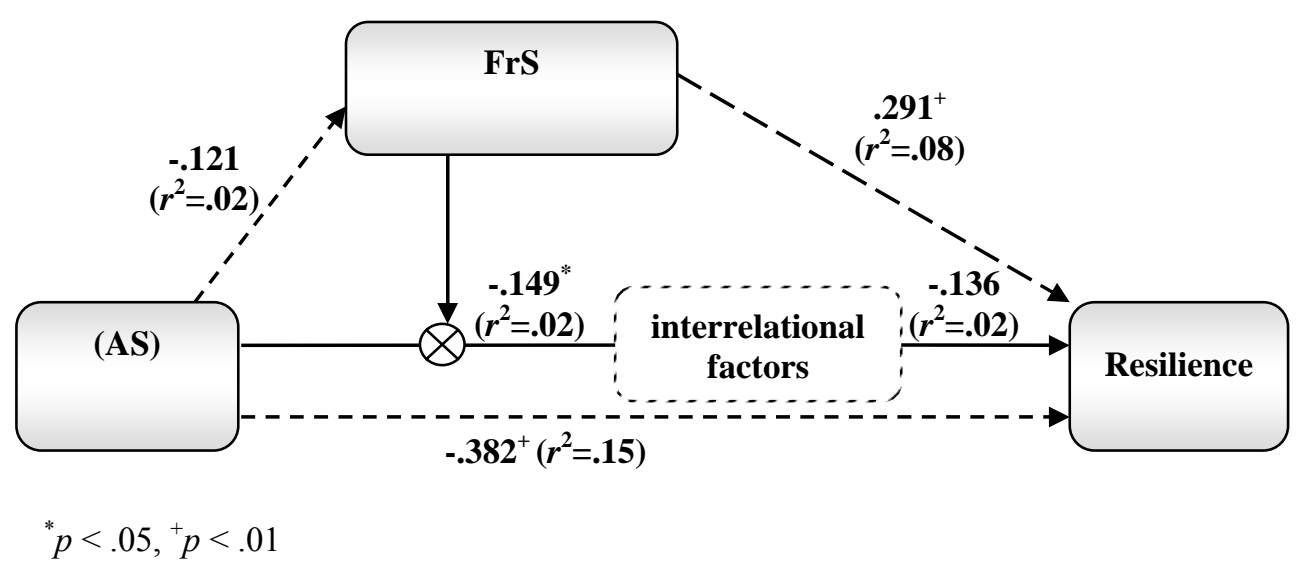

Abbreviations: AS - academic stress; FaS - family support; $\mathrm{FrS}$ - friend support

Figure 3 shows the path coefficients in the friend support moderation model. The moderation effect of AS $x$ FrS on the outcome was significant initially $(-.149, p<.05$, $\left.r^{2}=.02\right)$. Upon controlling for interrelational factors, the moderation effect loses significance though its negative effect to resilience reduces slightly $(-.136, p=.06$, $\left.r^{2}=.02\right)$.

\section{DISCUSSION}

Consistent with recent research (Ting et al., 2006), the current sample of social work students reported a moderate level of academic stress. Given this extent of stress, students reported a fairly high degree of resilience. This phenomenon of adaptational success amid substantial risk (stress) has been elucidated in past research (e.g., Werner \& Smith, 1992), at least in part, on the basis of protective resources that bolster adaptive functioning. The current study examined the protective nature of two resources: the magnitude of available family and friend support and their potential, moderating functions bounded concurrently by academic stress and resilience.

Students reported a fair amount of social support for both support systems - familial and friend. The primary variables significantly related to each other in expected directions. As highlighted in previous resilience research (Ortega et al., 2008; Rutter, 1990; Werner \& Smith, 1992), risk should exhibit a negative effect with resilience, while the protective factor often exhibits enhancing effect with resilience. Such was the case with the current results. The risk in the study, academic stress, inversely related with resilience, and both forms of social support positively related with resilience. All of these associations were moderately strong and empirically significant. 
Two, distinct moderation models were examined with family support and friend support as potential moderators. Moderation would indicate preliminary evidence of these support systems as protective factors of resilience. Results indicated that family support did not significantly moderate the negative relationship between academic stress and resilience. This lack of significance is noteworthy. The amounts of family and friend support reported among the sample were reportedly comparable; yet the utility of these support systems were divergent (see later discussion on friend support). Hence, quantity of social support does not equal similar functioning. Previous research (Zaleski et al., 1998) found a similar result with family support. They speculated that the youthful age (18.3 years) of their student sample and lack of emotional independence during the early transition to college contributed to family support's lack of moderating efficacy. The current study's sample revealed a larger mean age (26 years) and college longevity (54\% graduate students), calling to question the aforementioned justifications posited by Zaleski and her colleagues. Psychological developmental theories may offer reasoning for lack of moderating, protective functioning of family support. Traditional college-age students want to leave the family home, physically and psychologically. Developmental stage theories like Erikson's (1968) and Loevinger's (1994) assert that during the typical college years, the individual enters a life phase of finding oneself, detaching from family identity and forming friendships independent of family conformity. Further speculation on the statistical shortcoming of family support can be expansive and deficit-focused. Instead, the discussion shifts to the factor that exhibited moderation.

Friend support significantly moderated the relationship between academic stress and resilience. The negative effect of academic stress with resilience was tempered upon the interaction of friend support with stress. This result corresponds to previous theoretical and empirical research that remark on the positive value of friend support as a coping resource (Forte, 1995; Zaleski et al., 1998) and resource that is deemed protective of resilience (Tusaie, Puskar, \& Sereika, 2007).

The result of friend support moderation is notable, but it should be noted vigilantly. The student's relationships at home (marital status, children), at work (employment status), and at school (enrollment status, academic level) exerted extraneous influence on the moderation effect; when the influence was controlled, the significance of that effect waned. This is an interesting finding. Friend support is evidently more apt to moderate the stress of academia on the student's perceived ability to overcome stress during real life settings, i.e., when relational factor(s) are present, rather than controlled, statistical settings. It is logical to speculate that the student may not recognize academic stress as an independent stressor, or even a stressor at all, when other relational stressors are perceived at the forefront. Milner and Criss (2006) noted that many social work students bear an overarching sense of stress simply by being a social work major. It may be difficult for social work students (or any population, for that matter) to categorize stress into autonomous segments, and for the social work student, the stress of academia may be one segment in a larger, more ambiguous fusion of overall life stress.

These findings bear implications on social work faculty and field agency practitioners. It should be no surprise to faculty that the current study revealed a substantial amount of students' academic stress. Ting et al. (2006) noted that students in 
helping professions such as social work may experience higher stress than their cohorts in other disciplines because of the "additional responsibility of helping others" (p. 40). Social work students regularly discuss their academic stress, e.g., workload, upcoming deadlines and overall stress levels, among their classmates and faculty in the classroom setting (Milner \& Criss, 2006). Yet, social work faculty, though sympathetic and interested in enhancing student coping, are reluctant to modify the academic environment (Reeser, MacDonald, \& Wertkin, 1992). Given the tight windows of time that faculty face in disseminating course content and the student-teacher boundaries that must remain intact, there are still ways that social work faculty may dissipate this stress. Milner and Criss (2006) offered faculty a number of simple yet effective stress-relieving suggestions for their students in class, including the following:

- allow students an occasional venting process, i.e., brief, general discussions about stress associated with the academic lifestyle;

- encourage students to identify and empathize with each others' feelings; and

- create a regular ritual to begin classes, e.g., moment of silence to allow for the student's personal prayer or reflection.

All of the aforementioned suggestions point to the faculty member's commitment to appropriate student expression in the classroom, whereby the student may "find validation for the stress and difficulties they share" (Milner \& Criss, 2006, p. 18). This commitment to encourage student expression is supported by the Council on Social Work Education's (2008) educational policy on the student's active participation toward professional development.

Despite the stress, social work students characterized themselves with a strong level of resilience. It is unlikely that their perceived abilities to overcome stress exist by chance. The current study demonstrates the likelihood that social support, namely that from friends, plays a role in this resilience perception. Social work faculty can enhance friendship support by fostering connectedness in the classroom (Milner \& Criss, 2006). This can be accomplished by a number of methods, including class seating arrangement; group project assignments; and encouraging study groups as a pre-assignment, social learning tool and as a post-assignment, stress debriefing tool. These findings also emphasize the need for field agency practitioners to inform practicum students on protective resources, including social support systems, which may create awareness to the rigors of practice stress beyond the logistics of particular agency duties. As Maidment (2003) poignantly stated, students need "access to preparation and placement integration material that (is) less about what they might do on placement and more about the processes of learning and managing stress while working in a contemporary agency environment" (p. 57).

\section{LIMITATIONS AND FUTURE RESEARCH}

Common to survey research with students, data was collected in class by the instructor. This setting enhances sample size, but also runs the usual risks of (a) 
inadvertently creating a sense of academic bias toward some students for participation, and (b) receiving skewed data based on survey completion in a group setting. The survey cover letter assured the contrary to the aforementioned bias, yet the efficacy of this safeguard remains indefinite. Future studies with social work students with data collection sites outside of the classroom setting may minimize a Hawthorne effect (Merrett, 2006) and yield possibly truer results.

Results on the RS15 displayed limited distribution of resilience responses. While the reported high level of RS15 scores is informative in terms of a descriptive appreciation of the sample's elevated self-perception of successful adjustment, it may be difficult to generalize results from the moderation model given this limited variation in outcome scores. Perhaps a larger sample of social work students would lend disparity in resilience scores and increase generalizability.

The effect sizes $\left(r^{2}\right)$ in the moderation models were low in this study. Though moderation was deemed statistically significant in the friend support model, the nominal effect size suggests extraneous influence of moderation by other factors uncontrolled in the current study.

The present study's sample revealed limited diversity in terms of gender, ethnicity, and enrollment status. As such, observing no significant demographic differences in outcome scores is a restricted observation. Future studies with increased heterogeneity in sample characteristics would allow for increased understanding of social work student resilience with demographic breadth.

\section{CONCLUSION}

The author of this study has attempted to provide insight into the resilience of social work students amid a common source of stress and potentially protective, social resources. Results demonstrated that the support of friends moderates the negative relationship between academic stress and resilience. The author hopes that recognition of moderating resources such as friend support may help social work educators and professionals design and target more effective interventions to improve academic and health outcomes for their students.

\section{References}

Aldwin, C. M. (1994). Stress, coping, and development: An integrative perspective. New York: Guilford.

Arthur, N. (1998). The effects of stress, depression, and anxiety on postsecondary students' coping strategies. Journal of College Student Development, 39, 11-22.

Balk, D. E. (1995). Adolescent development: Early through late adolescence. Monterey, CA: Brooks/Cole.

Baron, R. M., \& Kenny, D. A. (1986). The moderator-mediator distinction in social psychological research. Journal of Personality and Social Psychology, 51, 11731182. 
Burnett, P. C., \& Fanshawe, J. P. (1997). Measuring school-related stressors in adolescents. Journal of Youth and Adolescence, 26(4), 415-428.

Cahir, N., \& Morris, R. (1991). The psychology student stress questionnaire. Journal of Clinical Psychology, 47, 414-417.

Campbell-Sills, L., Cohan, S. L., \& Stein, M. B. (2006). Relationship of resilience to personality, coping and psychiatric symptoms in young adults. Behaviour Research and Therapy, 44, 585-599.

Carver, C. S. (1998). Resilience and thriving: Issues, models, and linkages. Journal of Social Issues, 54, 245-266.

Clifton, R. A. (1997). The effects of social psychological variables and gender on the grade point averages and educational expectations of university students: A case study. The Canadian Journal of Higher Education, 27, 67-90.

Clifton, R. A., Perry, R. P., Stubbs, C. A., \& Roberts, L. W. (2004). Faculty environments, psychosocial dispositions, and the academic achievement of college students. Research in Higher Education, 45, 801-828.

Council on Social Work Education. (2006). Directory of accredited social work degree programs. Alexandria, VA: Author. Retrieved on February 10, 2007, from http://cswe.org.

Council on Social Work Education. (2008). Educational policy and accreditation standards. Retrieved May 1, 2008, from http://www.cswe.org/CSWE/accreditation.

Demakis, G. J., \& McAdams, D. P. (1994). Personality, social support and well-being among first year college students. College Student Journal, 28, 235-243.

Dolbier, C. L., \& Steinhardt, M. A. (2000). The development and validation of the sense of support scale. Behavioral Medicine, 25(4), 169-179.

Dziegielewski, S. F., Roest-Martl, S., \& Turnage, B. (2004). Addressing stress with social work students: A controlled evaluation. Journal of Social Work Education, 40, 105-119.

Erikson, E. (1968). Identity: Youth and crisis. New York: Norton.

Ford, G. G., \& Procidano, M. E. (1990). The relationship of self-actualization to social support, life stress, and adjustment. Social Behavior and Personality, 18, 41-51.

Forte, J. (1995). Teaching statistics without sadistic. Journal of Social Work Education, 31, 204-218.

Gelman, C. R. (2004). Anxiety experienced by foundation-year MSW students entering field placement: Implications for admissions, curriculum, and field education. Journal of Social Work Education, 40, 39-54.

Ginsberg, J., \& Gapen, M. (2008). Academic worry as a predictor of sleep disturbance in college students. Journal of Young Investigators, 18. Retrieved April 30, 2008, from http://www.jyi.org/research/re.php?id=708. 
Glass, D., \& Singer, J. (1972). Urban stress: Experiments on noise and social stressors. New York: Academic Press.

Haines, M. E., Norris, M. P., \& Kashy, D. A. (1996). The effects of depressed mood on academic performance in college students. Journal of College Student Development, $37,519-526$.

Heiman, T. (2006). Social support networks, stress, sense of coherence and academic stress of university students with learning disabilities. Social Psychology of Education, 9, 461-478.

Hubbard, P., Muhlenkamp, A. F., \& Brown, N. (1984). The relationship between social support and self-care practices. Nursing Research, 33, 266-270.

Kamya, H. A. (2000). Hardiness and spiritual well-being among social work students: Implications for social work education. Journal of Social Work Education, 36, 231240 .

Kariv, D., \& Heiman, T. (2005). Task-oriented versus emotion-oriented coping strategies: The case of college students. College Student Journal. Retrieved February 9, 2007, from http://www.findarticles.com/p/articles/mi_m0FCR/is_1_39/ai_n13603935.

Kohn, J. P., \& Frazer, G. H. (1986). An academic stress scale: Identification and rated importance of academic stressors. Psychological Reports, 59(2), 415-426.

Kobasa, S. (1979). Stressful life events, personality, and health: An inquiry into hardiness. Journal of Personality and Social Psychology, 37, 1-11.

Loevinger, J. (1994). Has psychology lost its conscience? Journal of Personality Assessment, 62, 2-8.

Losel, F., \& Bliesener, T. (1990). Resilience in adolescence: A study on the generalizability of protective factors. In K. Hurrelmann \& F. Losel (Eds.), Health hazards in adolescence (pp. 299-320). New York: deGruyter.

MacGeorge, E. L., Samter, W., \& Gillihan, S. J. (2005). Academic stress, supportive communication, and health. Communication Education, 54, 365-372.

Maidment, J. (2003). Problems experienced by students on field placement: Using research findings to inform curriculum design and content. Australian Social Work, $56,50-60$.

Martinelli, A. M. (1999). An explanatory model of variables influencing health promotion behaviors in smoking and nonsmoking college students. Public Health Nursing, 16(4), 263-269.

Masten, A. S. (2001). Ordinary magic: Resilience processes in development. American Psychologist, 56, 227-238.

Maton, K. I., Teti, D. M., Corns, K. M., Vieira-Baker, C. C., Lavine, J. R., et al. (1996). Cultural specificity of support sources, correlates and contexts: Three studies of 
African-American and Caucasian youth. American Journal of Community Psychology, 24, 551-587.

Merrett, F. (2006). Reflections on the Hawthorne effect. Educational Psychology, 26, 143-146.

Milner, M., \& Criss, P. (2006, October). Use of spiritual practices and classroom rituals of connection to reduce impact of stress in social work students. Presented at the National Association of Christian Social Workers 2006 Convention, Philadelphia, PA.

Misra, R. (2000). Academic stress of college students: Comparison of student and faculty perceptions. College Student Journal, 21, 1-10.

Misra, R., McKean, M., West, S., \& Russo, T. (2000). Academic stress of college students: Comparison of student and faculty perceptions. College Student Journal, 34, 236-245.

Mori, S. (2000). Addressing the mental health concerns of international students. Journal of Counseling and Development, 78, 137-144.

Negga, F., Applewhite, S., \& Livingston, I. (2007). African American college students and stress: School racial composition, self-esteem and social support. College Student Journal, 41, 823-830.

Neill, J. T., \& Dias, K. L. (2001). Adventure education and resilience: A double-edged sword. Journal of Adventure Education and Outdoor Leadership, 1(2), 35-42.

Ortega, S., Beauchemin, A., \& Kaniskan, R. B. (2008). Building resiliency in families with young children exposed to violence: The Safe Start Initiative pilot study. Best Practices in Mental Health, 4, 48-64.

Pottage, D., \& Huxley, P. (1996). Stress and mental health social work: A developmental perspective. International Journal of Social Psychology, 42, 124-131.

Procidano, M. E., \& Heller, K. (1983). Measures of perceived social support from friends and from family: Three validation studies. American Journal of Community Psychology, 11, 1-24.

Rayle, A. D. (2006). Mattering to others: Implications for the counseling relationship. Journal of Counseling \& Development, 84, 483-487.

Reeser, L., MacDonald, F., \& Wertkin, R. (1992). Enhancing student coping and modifying the stressful academic environment. Journal of Teaching in Social Work, 6, 87-97.

Rompf, E. L., Royse, D., \& Dhooper, S. S. (1993). Anxiety preceding field work: What students worry about. Journal of Teaching in Social Work, 7, 81-95.

Rosenblatt, A., \& Mayer, J. E. (1975). Objectionable supervisory styles: Student views. Social Work, 20, 184-189. 
Rutter, M. (1990). Psychosocial resilience and protective mechanisms. In J. Rolf, A. Masten, D. Cicchetti, K. Neuchterlein \& S. Weintraub (Eds.), Risk and protective factors in the development of psychopathology (pp. 181-214). New York: Cambridge University Press.

Sarason, B. R., Shearin, E. N., Pierce, G. R., \& Sarason, I. G. (1987). Interrelations of social support measures: Theoretical and practical implications. Journal of Personality and Social Psychology, 52, 813-832.

Shute, C. L., \& Spitzberg, B. H. (2003, June). Intercultural couples: Examining the role of social support. Paper presented at Hawaii International Conference on Social Sciences, Honolulu, HI.

Skehill, C. M. (2001). Resilience, coping with an extended stay outdoor education program, and adolescent mental health. Retrieved January 2, 2007, from http://wilderdom.com/pdf/Skehill2001ResilienceCopingOutdoorEducation.pdf

Steinhardt, M., \& Dolbier, C. (2008). Evaluation of a resilience intervention to enhance coping strategies and protective factors and decrease symptomatology. Journal of American College Health, 56, 445-453.

Sun, A. (1999). Issues BSW interns experience in their first semester's practicum. The Clinical Supervisor, 18, 105-123.

Tennant, C. (2002). Life events, stress, and depression. Australian and New Zealand Journal of Psychiatry, 36, 173-182.

Ting, L., Morris, K. J., McFeaters, S. J., \& Eustice, L. (2006). Multiple roles, stressors, and needs among baccalaureate social work students: An exploratory study. Journal of Baccalaureate Social Work, 12, 39-55.

Tobin, P. J., \& Carson, J. (1994). Stress and the student social worker. Social Work \& Social Sciences Review, 5, 246-255.

Tugade, M., Fredrickson, B., \& Barrett, L. (2004). Psychological resilience and positive emotional granularity. Journal of Personality, 72, 1161-1190.

Tusaie, K., Puskar, K., \& Sereika, S. (2007). A predictive and moderating model of psychosocial resilience in adolescents. Journal of Nursing Scholarship, 39, 54-60.

Von Ah, D., Ebert, S., Ngamvitroj, A., Park, N., \& Kang, D. (2004). Predictors of health behaviors in college students. Journal of Advanced Nursing, 48(5), 463-474.

Wang, P. P., Badley, E. M., Gignac, M. (2006). Exploring the role of contextual factors in disability models. Disability and Rehabilitation, 28, 135-140.

Ward Struthers, C., Perry, R. P., \& Menec, V. H. (2000). An examination of the relationship among academic stress, coping, motivation, and performance in college. Research in Higher Education, 41(5), 581-592.

Werner, E. E., \& Smith, R. S. (1992). Overcoming the odds: High risk children from birth to adulthood. Ithaca, NY: Cornell University Press. 
Zaleski, E. H., Levey-Thors, C., \& Schiaffino, K. M. (1998). Coping mechanisms, stress, social support, and health problems in college students. Applied Developmental Science, 2(3), 127-137.

\section{Author's note:}

Address correspondence to: Scott E. Wilks, Ph.D., School of Social Work, Louisiana State University, 203 H.P. Long Fieldhouse, Baton Rouge, LA 70803. E-mail: swilks@1su.edu 